\title{
Den digitaliserede Kulturarv \\ - En læringsressource med stort potentiale!
}

\section{Jørgen Bang}

Lektor.

Institut for Informations- og Medievidenskab, Aarhus Universitetet

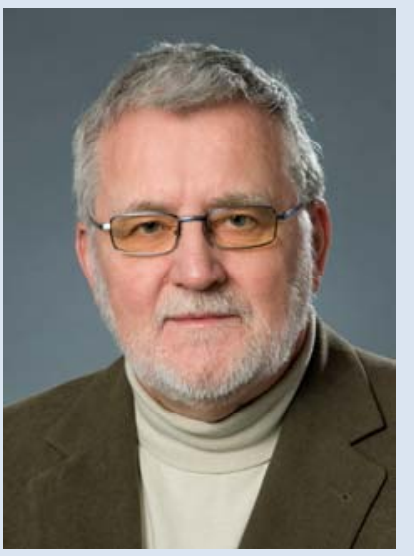

\section{Abstract}

Artiklen diskuterer læringspotentialet i den digitaliserede kulturarv dels i et kulturelt perspektiv (kulturarv som national, europæisk og global indikator med potentiale for øget identitetsdannelse og mellemfolkelig forståelse), dels i et læringsteoretisk perspektiv (store åbne læringsressourcer som udgangspunkt for læringsaktiviteter med fokus på samarbejde i problembaseret projektarbejde). Udgangspunktet tages i den nye europæiske database for den digitaliserede kulturarv "Europeana" og 
erfaringer fra et dansk digitaliseringsprojekt vedrørende digitalisering af biografreklamefilm og TV2 reklamer.

Samtidig fokuserer artiklen på behovet for at udvikle/integrere nye samarbejdsværktøjer i læreprocessen (Web 2.0, annoterings-, segmenteringsog genkendelsesværktøjer, mm.) med henblik på samarbejde som en integreret del af læringsaktiviteterne.

Sidst i artiklen diskuteres det om en øget adgang til digitale læringsressourcer, der kan udbygges med brugergenereret indhold og øget tilgængelighed via fremtidens mobile teknologier, rummer et potentiale for en ny oplysningstid!

\section{Europeana - det europæiske digitale bibliotek}

Den 20. november 2008 lancerede EU et nyt digitalt bibliotek med 2 millioner digitale objekter - og samme dag gik dets web-site www.europeana.eu ned på grund af en enorm interesse med mere end 10 millioner hits i timen. Det siger noget om interessen for at få adgang til den europæiske kulturarv. Det samme gentog sig da Aarhus Universitet i maj 2009 åbnede hjemmesiden www.danmarkshistorien.dk - omend i mindre målestok.

I januar 2009 lykkedes det at få Europeana op at køre og siden har der ikke været problemer. Målet er at 10 millioner digitale objekter fra den europæiske kulturarv skal være tilgængelige i databasen i løbet af 2010. Desværre er chancen for at møde den danske kulturarv i basen meget begrænset. Som det fremgår af Politikens kronik fra 30. april 2009, skrevet af lederne af de største danske kulturinstitutioner, er der ikke afsat særlige midler til at digitalisere den danske kulturarv.

Hvor store forventningerne er til at Europeana kan bidrage til det europæiske integrationsprojekt, fremgår tydeligt af den pressemeddelelse som blev udsendt den 19. november med en række udtalelser fra kommissions medlemmer og projektets leder:

\footnotetext{
"José Manuel Barroso, President of the European Commission, said: "With Europeana, we combine Europe's competitive advantage in communication and networking technologies with our rich cultural heritage. Europeans will now be able to access the incredible resources of our great collections quickly and easily in a single space. Europeana is much more than a library, it is a veritable dynamo to inspire 21st century Europeans to emulate the creativity of innovative forbears like the drivers of the Renaissance. Just imagine the possibilities it offers students,
} 
art-lovers or scholars to access, combine and search the cultural treasures of all Member States online. This is a strong demonstration of the fact that culture is at the heart of European integration."

\begin{abstract}
"Europeana offers a journey through time, across borders, and into new ideas of what our culture is. More than that, it will connect people to their history and, through interactive pages and tools, to each other," said Viviane Reding, EU Commissioner for Information Society and Media. "I now call on Europe's cultural institutions, publishing houses and technology companies to fill Europeana with further content in digital form. We should make Europeana a home for interactive creative participation at the fingertips of people who want to mould their own piece of European culture and share it with others. My objective is that in 2010, Europeana will include at least 10 million objects."
\end{abstract}

Elisabeth Niggemann, Director-General of the German National Library and chair of the European Digital Library Foundation - the organisation behind Europeana -, added:

"Europeana makes cultural bodies more relevant to the Web 2.0 generation - a generation that expects to be able to read text, see video, hear sounds and view images all in the same space and time. By offering young people a complete multimedia experience it will connect them to Europe's culture, past and present."

"Europeana makes it possible to search and browse the digitised collections of Europe's libraries, archives and museums all at once. This means users can explore themes without searching for and visiting multiple sites and resources."

(http://europa.eu/rapid/pressReleasesAction.do?reference=IP/08/1747\& format $=$ HTML\&aged=0\&language $=$ EN\&guiLanguage $=$ en)

Europeana er kulminationen på en indsats som har stået på i flere år for at digitalisere den kulturelle arv, der opbevares på museer, biblioteker og arkiver i Europa. Målet er dels at bevare kulturarven for eftertiden, dels at gøre den tilgængelig for forskning, uddannelse og videnstilegnelse i bred forstand.

Europeana er ikke et eksempel på en ny europæisk gigant-institution, men er derimod et samarbejdsprojekt, som bygger på digitaliseringer af den 
nationale kulturarv i de enkelte lande, som sammenkobles i et fælles europæisk kulturarvsprojekt.

Projektet rummer således på engang både en national og en europæisk dimension, som kan bidrage til identitetsforståelsen - selvforståelsen - hos indbyggerne i de europæiske lande. Som samfundsborgere får vi mulighed for at forstå os selv som del af en nationale kultur, der samtidig er en del af en europæisk kultur!
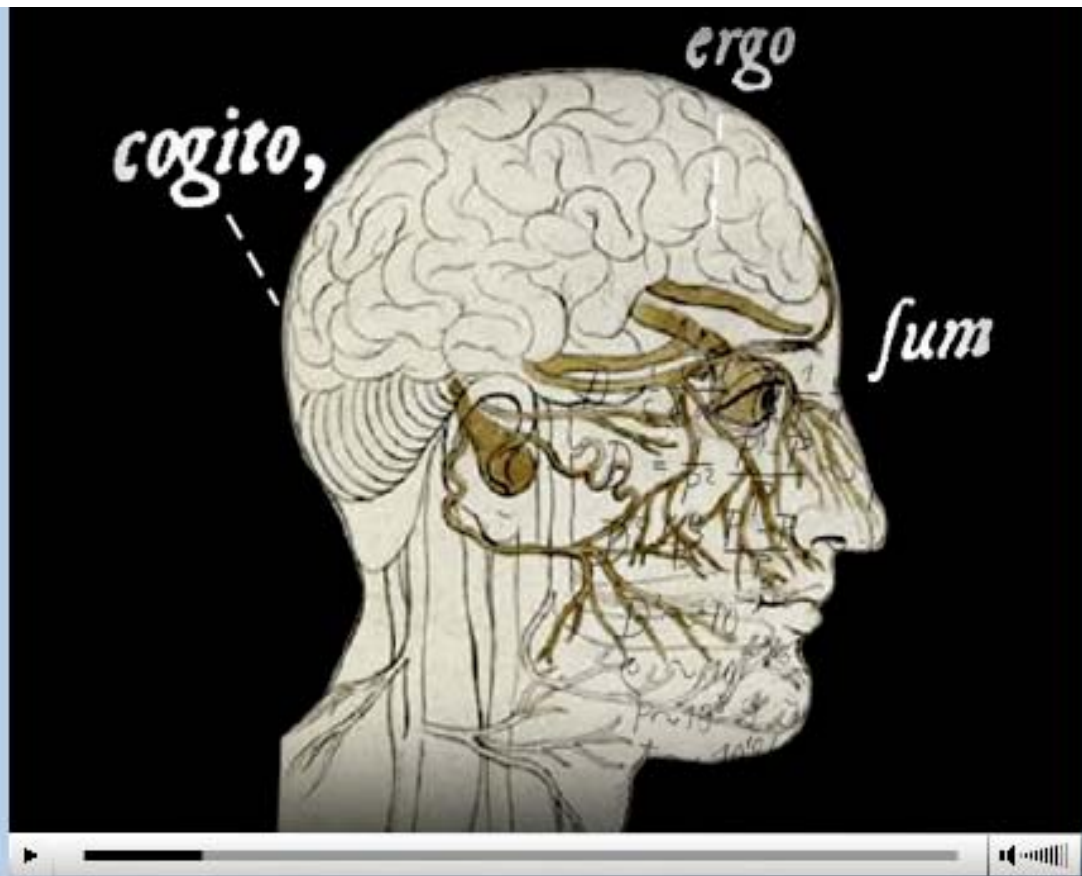

Here's the storyline and credits

Click here to close the video

\section{New Europeana demo}

Take a tour of the new Europeana site: a set of screenshots shows you what you can expect to see and hear on the new site.

\section{click to play demo}

Figur 1. Europeane demo: http://europeana.eu/portal/aboutus.html

Mærkeligt nok fremhæves det ikke eksplicit i ovenstående begejstrede omtale af Europeana at brugen af database til kulturel udforskning og europæiske identitetsdannelser er en læreproces, som foregår både i 
uformelle og formelle sammenhænge - $\mathrm{i}$ forbindelse med kulturtilbud i fritiden og i planlagte undervisningsforløb på uddannelsesinstitutionerne. I det lys er Europeana en enorm åben læringsressource - og som sådan vil jeg diskutere dens muligheder i det følgende.

\section{Den digitaliserede kulturarv som læringsressource}

I et læringsperspektiv åbner adgangen til den digitaliserede kulturarv mange nye muligheder. Den hurtige og lette adgang til de digitale ressourcer gør det muligt løbende at inddrage objekterne i forskellige tematiske undervisnings- og læringssammenhænge. F. eks kan malerier fra museer, tableauer fra egnsmuseer og tekster fra biblioteker perspektivere læsningen af litterære tekster fra forskellige perioder.

Samtidig rejser dette imidlertid et mere principielt læringsteoretisk spørgsmål: Kan den digitaliserede kulturarv - og dens digitale objekter betragtes som læringsressourcer?

Ud fra en klassisk elæringssynsvinkel vil den digitaliserede kulturarv ikke blive betragtet som læringsobjekter eller som læringsressourcer før der er sket en pædagogisk tilpasning af materialet. I denne optik opfattes den pædagogiske designproces som essentiel for at viden kan overføres fra materialet til den lærende - og samtidig næsten også som garant for at det faktisk sker. Spørgsmålet er imidlertid om denne model for "resourcebased learning", som har haft en betydelig succes i korte "just-in-time" og "just-in place"-kurser, giver et korrekt billede af læreprocessen. Min opfattelse ligger på linje med Rob Kopers fra forskningsenheden på det hollandske åbne universitet, når han gør op med inspirationen fra "educational instructional design"-teorien (2000) og efterfølgende (2001) påpeger at læringsaktiviteten er afgørende for læring:

"Instructional design is based on the empiric assumption that behaviour is predictable, and that educational design, therefore, can occur in isolation from educational execution." (Koper, 2000 p.14), men

“(...) a lot of learning does not come from knowledge resources at all, but stems from the activities of learners solving problems, interacting with real devices, interacting in their social and work situation. (...) it is the activities of the learners into the learning environment, which are accountable for the learning." (Koper, 2001 p.3).

I et arbejdspapir fra Projektet: "Framework for eLearning Contents Evaluation (FeConE)" (2007) udbygger Andreas Kollias denne sammenhæng mellem indholdet i en læringsressource og aktiviteten i læreprocessen: 


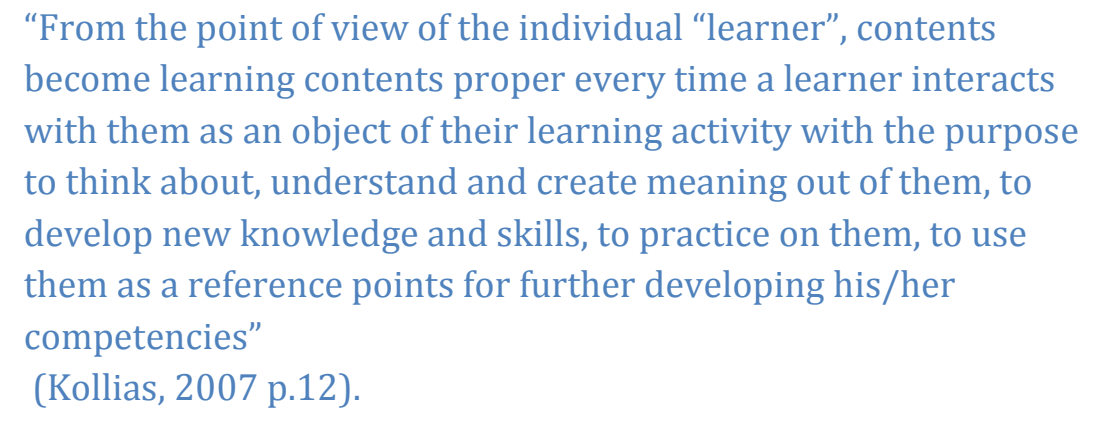

Alt indhold - alle materialer - bliver altså til en læringsressource, når de indgår i en læreproces, hvor den lærende forholder sig aktivt og konstruktivt bruger ressourcen. Læring er ikke indbygget i indholdet. Læring sker i den lærende som et resultat af at han eller hun bearbejder indholdet aktivt og sætter det i relation til den viden, som allerede er opbygget. I læreprocessen er der et dialektisk samspil mellem læringsressoucer og læringsaktiviteter, hvor den mest basale læringsaktivitet er en dialog mellem den lærende og indholdet.

I følge dette ræsonnement er der altså ingen tvivl om at den digitaliserede kulturarv er at betragte som en læringsressource, når den aktiveres i en læreproces. Det kan ske i formelle læreprocesser organiseret via uddannelsesinstitutioner, hvor lærere har et betydeligt ansvar for at iværksætte relevante læringsaktiviteter, eller i uformelle læreprocesser i form af udstillinger og/eller publikationer, hvor den lærendes aktivitet udspringer af brugerens vakte nysgerrighed.

Det er min opfattelse at samlinger i museer, biblioteker og arkiver allerede er at betragte som læringsressourcer før de bliver digitaliserede. Digitaliseringen er med andre ord blot en måde at øge tilgængeligheden på, hvorved kulturarven kan tilgås uafhængigt af tid og sted og dermed bidrage til realiseringen af den vision som Vivian Reding ser: "Europeana offers a journey through time, across borders, and into new ideas of what our culture is. More than that, it will connect people to their history and, through interactive pages and tools, to each other".

\section{Åbne læringsressourcer og virtuelle universiteter}

Europeana er lanceret som et kulturelt initiativ med henblik på øget kulturel og interkulturel forståelse i Europa, ikke som et uddannelsesinitiativ. Alligevel er det interessant at se hvor tæt Europeana lægger sig op ad de initiativer, som pågår inden for uddannelsessektoren for at skabe åbne læringsressourcer - Open Educational Resources (OER).

I 2001 lancerede MIT ideen som "MIT OpenCourceWare Intiative" - og i 2007 har OECD i sin rapport "Giving Knowledge for Free. The Emergence of Open Educational Resources" identificeret 300 universiteter som udbyder 
ca. 3000 kurser i henhold til dette koncept, samt yderligere 20.000 "open learning objects" som er tilgængelige i såkaldte "open repositories".

Denne udvikling er støttet af Hewlett Foundation som siden 2002 har investeret \$ 68 millioner i projekter, der genererer åbne uddannelsesressourcer. EU støtter også ideen om åbne læringsressourcer i blandt andet OLCOS (Open eLearning Content Observatory Services) projektet - jf. deres vision for fremtiden: 'Roadmap 2012':

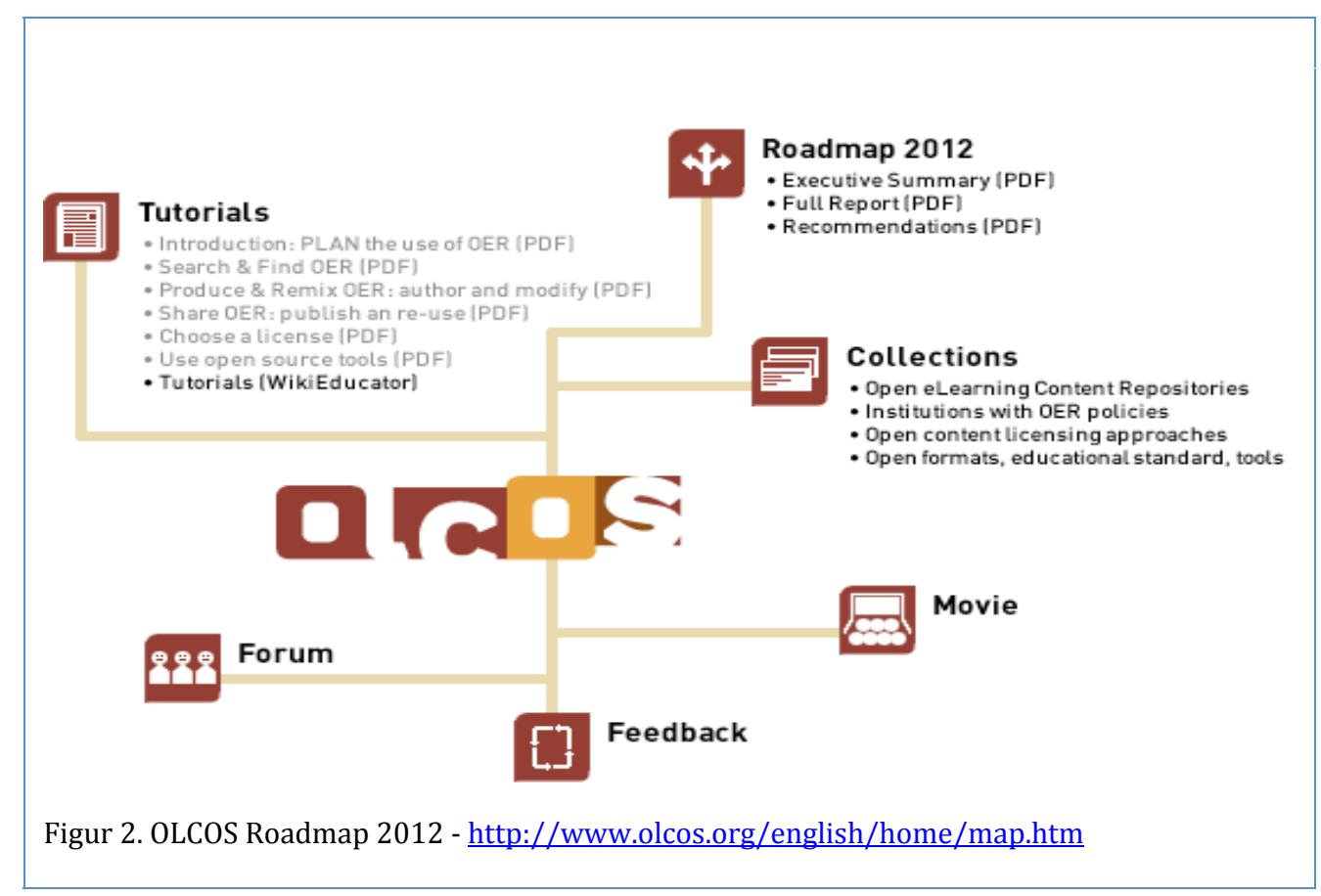

Paradoksalt nok sker denne satsning på åbne læringsressourcer inden for dele af uddannelsessektoren samtidig med at en række initiativer med fokus på oprettelsen af virtuelle universiteter baseret på elæring lider skibbrud.

På "eLearning Conference" i Bruxelles i maj 2005 karakteriserede Fabrizio Cardinalli fra Guinti Interactive Labs i Italien udviklingen inden for elæring i to faser:

1: "The big wave of elearning" i 1990'erne, hvor mange institutioner satsede på at opbygge virtuelle universiteter baseret på en tiltro til Peter Druckers forudsigelse fra 1997 at "universities won't survive ... as residential institutions. They will become producers of learningware for for-profit enterprises" (The Guardian, April 13, 2004).

2: "The Tsuanami of e-learning" efter årtusindeskiftet hvor adskillige virtuelle universiteter i både USA og Europa kuldsejlede. 
Kulminationen var lukningen af UK eUniversity i 2005 efter at der var tabt investeringer på $€ 60$ millioner (Bang 2006).

OECD har i flere rapporter analyseret udviklingen inden for elæring med henblik på at forstå hvorfor den ikke har levet op til forventningerne. I

2001 konstaterer de at

"(...) There is however no clear evidence that ICT investments made by the public sector have resulted in improved performance of teachers and/or learners, nor that it has improved the quality and access to educational resources on the scale predicted" (OECD 2001, p.24).

Rapporten lokaliserer meget overbevisende problemet til at

"Technology alone does not deliver educational success. It only becomes valuable in education if learners and teachers can do something useful with it."

(OECD 2001, p. 24-25).

Til trods for denne klare analyse af hvorfor der mangler pædagogiske resultater, mister OECD imidlertid ikke troen på, at elæring er fremtidens medie for læring. I 2001 udtrykkes det således:

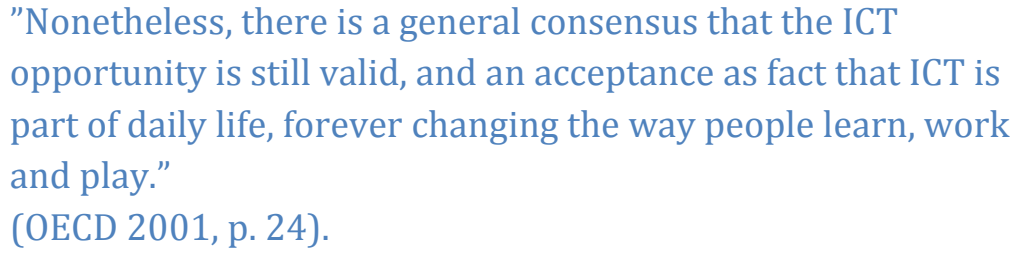

Nogle år senere præciserer en anden rapport at den pædagogiske gevinst ved at anvende ikt i undervisningen stadig er udeblevet:

\footnotetext{
"The current immaturity of online learning is demonstrated by low adoption of content management systems (...). ICT has penetrated tertiary education, but has had more impact on administrative services (e.g. admissions, registration, fee payment, purchasing) than on the pedagogic fundamentals of the classroom." (OECD, 2005 p. 14-15).
} 
En del af forklaringen på hvorfor "Tsunamien" skyllede henover og væltede adskillige virtuelle universiteter, der baserede deres pædagogiske og økonomiske model på elæring, synes at have været teknologifiksering. Elæringsprojekterne har i stor udstrækning været teknologidrevne med henblik på at opnå en rationaliseringsgevinst. Samtidig har de også været topstyret.

Når andre universiteter i de samme år tilsyneladende har haft succes med at lægge deres læringsressourcer ud åbent og frit tilgængeligt på internettet, kan det meget vel skyldes at disse projekter er altruistiske, pædagogikdrevne og vokset op fra bunden. Incitamentet synes at være at brugerne kan anvende de åbne ressourcer til noget!

Samtidig synes de nye teknologier, kendt som "social software" eller Web 2.0, at tilbyde nye former for samarbejde, som kan overvinde de pædagogiske problemer som elæring tidligere har tumlet med. I en statusrapport fra 2007 "A Review of the Open Educational Resources (OER) Movement: Achievements, Challenges, and New Opportunities" (Atkins a.o., 2007) peger Hewlett Foundation på behovet for en videreudvikling af samarbejdsformer i læreprocessen i en såkaldt " open participatory learning infrastructure (OPLI)":

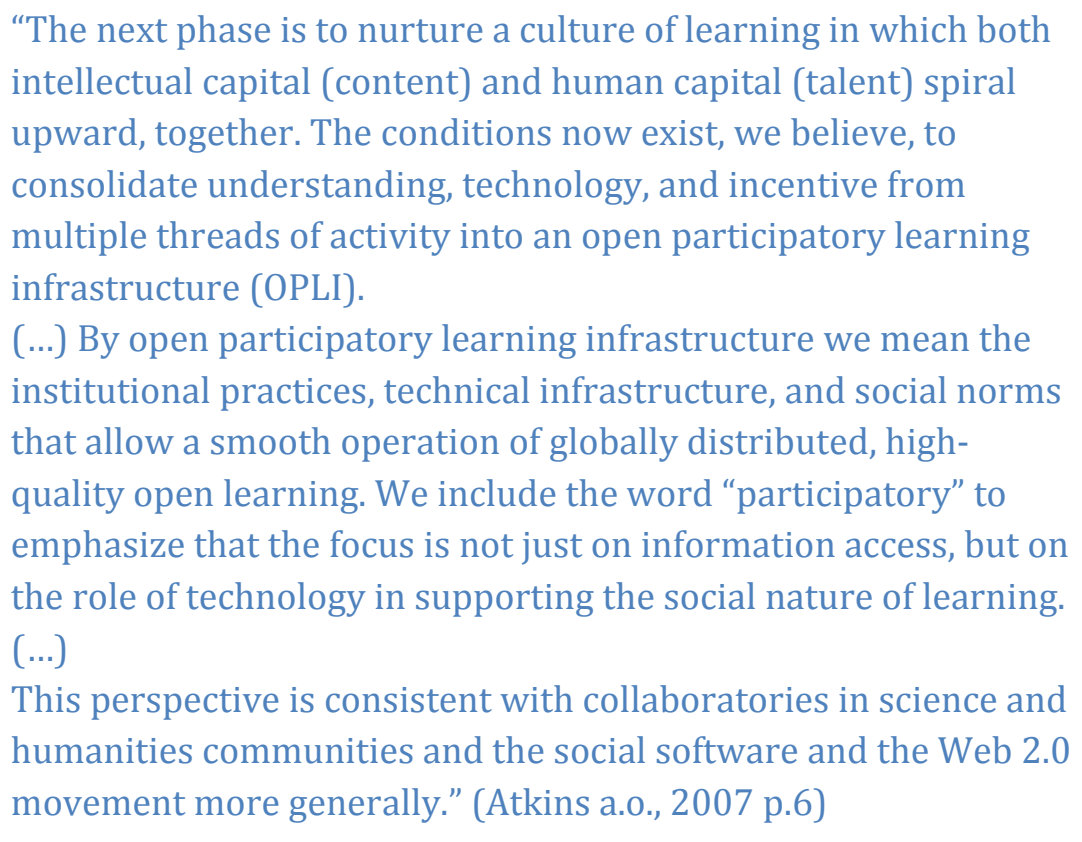

I det følgende vil jeg se nærmere på de læringspotentialer som ligger i den digitaliserede kulturarv med udgangspunkt i et dansk digitaliseringsprojekt, for derefter at gøre nærmere rede for den forståelse af læreprocessen, som er nødvendig for at udnytte dette potentiale. 


\section{Reklamefilm som digitaliseret kulturarv}

Danske Reklamefilm er en database i Statsbibliotekets samling som indeholder ca. 4000 danske biografreklamefilm fra 1910'erne og frem til 1995, samt ca. 50.000 tv-reklamer sendt af TV2 siden 1988. De resterende biografreklamer fra 1995 til i dag samt de sidste TV2-reklamer forventes indført i databasen i foråret 2009. Databasen er resultatet af et projekt mellem Statsbiblioteket i Århus og Aarhus Universitet, Institut for Informations- og Medievidenskab som i perioden 2002-07 har været støttet af Forskningsrådet for Kultur og Kommunikation. Digitaliseringen af TV2-reklamerne blev finansieret af midler fra Kulturministeriet, som stammer fra salget af UTMS-licenser og er dedikeret til bevarelsen af den danske kulturarv.

Projektet havde 3 mål:

1: at samle og bevare de gamle reklamefilm

2: at undersøge de nye forskningsmuligheder som adgangen til større mængder af digitaliserede kulturarvsmaterialer åbner for kulturforskningen

3: at skabe en digital læringsressource.

Det første mål er en klassisk biblioteksopgave. De gamle biografreklamefilm var i en ynkelig forfatning på grund af dårlige opbevaringsforhold. Som kommercielle produkter havde samtiden ikke ofret dem samme interesse som spillefilm og andre finkulturelle produkter. Derfor er det også kun en begrænset mænge af biografreklamer fra det 20 . århundrede som er bevaret. I forbindelse med digitaliseringen har det været nødvendig at foretage farvegenopretning på en række af filmene for at få en se-værdig udgave af dem.

Det andet formål: at undersøge muligheder for at gennemføre kulturhistorisk forskning på nye måder i og med at materialet nu foreligger i digital form, blev gennemført af forskere ved Institut for Informations- og Medievidenskab. Resultatet kan læses i p.o.v. 23, 2007 og på Statsbibliotekets hjemmeside http://www.statsbiblioteket.dk/tvradio/reklamefilm/litteraturliste.

Mit eget bidrag: "Short Narrative Advertising and Cultural Heritage. New Options for Cultural Study Research via Digitalisation" diskuterer blandt andet spørgsmålene: I hvilken udstrækning giver det mening at anskue biograf- og tv-reklamer som en del af den danske kulturarv? Og mere specifikt: Hvordan skal man analysere reklamer som kulturindikatorer? Samtidig giver den eksempler på hvordan husmoderrollen ændrer sig i danske biografreklamer i sidste del af det 20 . århundrede. 
To exemplify the changes in the concept of the housewife, I will present a small mosaic of images from four short narrative ads (inspired by the non-verbal chapters in John Berger's Ways of Seeing ). All the ads brand the same product from AJAX: "Liquid AJAX. Cleans like a white tornado" and its successor AXJA. Four images are chosen from each to illuminate the changes in the concept of the role-model housewife. I have called the mosaic "When the housewife turned into a male".

The four ads were released for showing at movie theatres in 1965 (playing 44 seconds), 1978 (playing 34 seconds), 1982 (playing 42 seconds) and 1987 (playing 30 seconds).
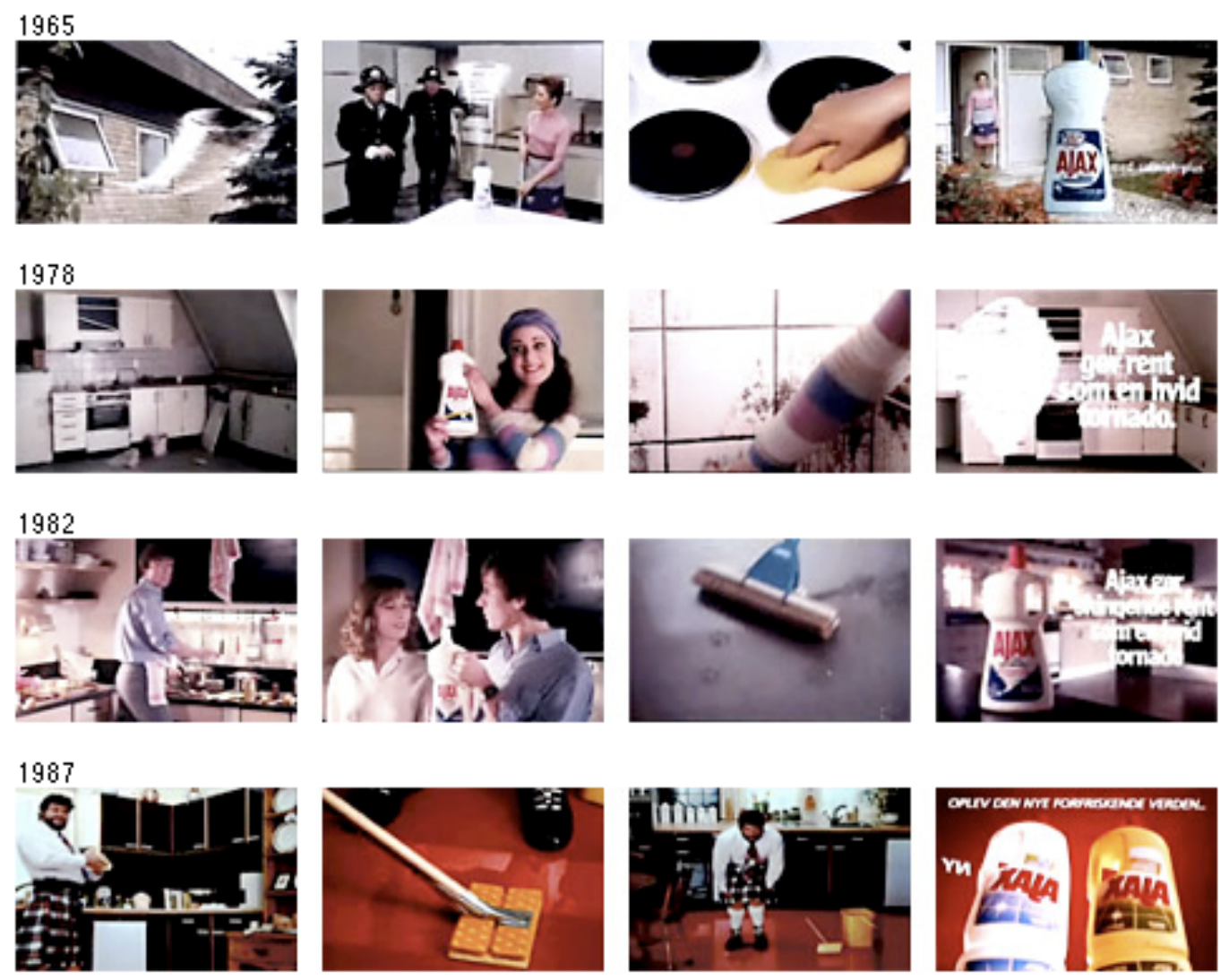

Figur 3. Husmoderrollen i forandring: http://pov.imv.au.dk/Issue 23/section 1/artc1A.html

Reklamer er populærkultur og som sådan sjældent provokerende eller satiriske; nogle gange ironiske og humoristiske, men aldrig ude af trit med den offentlige mening og generelt accepteret. Reklamer konstituerer et alment bevidsthedsniveau, der kan danne baggrund for at forstå kunstens udfordringer i samme periode. I det perspektiv rummer Danske Reklamefilm et enormt uddannelsesmæssigt potentiale ved at sætte kulturelle produkter som litteratur, malerkunst, film, teater, $\mathrm{mm}$. ind i et større samfundsmæssigt og kulturelt perspektiv. Samspillet mellem reklamens hverdagsbevidsthed og kunstens kritisk provokation eller 
mangel på samme fungerer som en øjenåbner i pædagogiske sammenhænge.

Projektets tredje mål: at skabe en digital læringsressource, er imidlertid begrænset af de copyright-bestemmelser, som de digitaliserede reklamefilm er underlagt. Materialet er kun frit og åbent tilgængeligt for besøgende på Statsbiblioteket. Et udvalg på 300 særligt interessante biografreklamer er gjort tilgængeligt for skoler mod en favorabel betaling. Dette udvalg vil i nærmeste fremtid blive suppleret med 5-600 interessante tv-reklamer. Der er ikke muligt at downloade disse videoer. De vises i en streamet udgave. Ikke desto mindre giver denne samling af digitale reklamer eleverne mulighed for at arbejde med opstilling og afprøvning af hypoteser om kulturelle forhold i Danmark fra 1910'erne og frem til i dag.

Hvis universiteter og professionshøjskoler abonnerer på adgang til databasen kan studerende, lærere og forskere få adgang til hele materialet til studie- og forskningsformål - og det i en downloadet udgave som muliggør tættere analytisk arbejde med teksterne (se nedenfor).

Anskuet som læringsressource rummer databasen Danske Reklamefilm en række mulige undervisningstemaer. De nævnte forskningstemaer, der følger forskellige spor i den kulturelle udvikling, f. eks. ændringer i familiemønstret, især med henblik på kvinderollen baseret på studier af reklamer for ingredienser til madlavning og rengøring, er også oplagte undervisningstemaer. Samtidig ligger det lige for at inddrage de digitale reklamer i undervisningen i markedsføringsstrategier i det 20. århundrede. En anden mulighed er at anvende materialet $i$ undervisningen i film og tv til at belyse udviklingen i det audiovisuelle sprog gennem de sidste 100 år. Dette er blot nogle få eksempler på utallige muligheder.

\section{Læringspotentialet i den digitaliserede kulturarv}

Ovennævnte eksempler fokuserer på de faglige - kulturelle, historiske, mediemæssige og markedsføringsmæssige - dimensioner som ligger i anvendelsen af de digitaliserede biograf- og tv-reklamer i pædagogiske sammenhænge.

I selve arbejdet med større mængder af digitaliserede ressourcer ligger der imidlertid også en almen pædagogisk dimension. Hvor kulturstudier tidligere byggede på analyser af mere eller mindre tilfældigt udvalgte eksempler, der blev anskuet som typiske, er det nu muligt at bearbejde store tematisk beslægtede tekstmængder. Den lærende har mulighed for alene eller i grupper - at opstille hypoteser og finde svar ved at søge og analysere store mængder af digitale data. Studerende kan arbejde problem-baseret og projektorienteret. Samtidig er selve kompetencen at analysere og bearbejde store digitale ressourcer i stigende grad central i videnssamfundet. 
Begejstringen for disse potentialer i de digitaliserede læringsressourcer bygger på en konstruktivistisk forståelse af læreprocessen. Som markeret ovenfor med henvisningen til Rob Koper er det ikke læringsressourcen i sig selv som sætter gang i læreprocessen men derimod den aktivitet, hvor den lærende anvender ressourcen til at skabe mening - m.a.o. bruger den til noget. Det kan ske i formelle undervisningssammenhænge hvor en lærer er igangsætter af meningsskabende læringsaktiviteter, eller det kan foregå i uformelle sammenhænge f. eks ved museums- og eller biblioteksbesøg, hvor den enkelte selv iværksætter sin læreproces ved at søge svar på spørgsmål, han eller hun selv finder interessante.

Viden er ikke noget som overføres fra en anden person eller fra en tekst til den lærende. Viden konstrueres af den lærende i samspil med læringsressourcen ved at integrere dens informationer med hans eller hendes eksisterende viden til en ny forståelse. Processen er ikke nødvendigvis social, men den fremmes i sociale netværk, fordi forståelsen faciliteres af dialogen gennem argumentationen.

Der er en pædagogisk åbenhed indbygget i databaser som Danske Reklamefilm. Det samme materiale kan anvendes i forskellige læringsscenarier og af forskellige brugere/studerende. Det er op til den erfarne lærer med kendskab til brugerne at opstille en ramme for læreprocessen og udstikke relevante læringsaktiviteter. På længere sigt kan man forestille sig at disse læringsaktiviteter lagres og forsynes med relevante metadata for eksempelvis faglige mål, klassetrin og tidsramme med henblik på erfaringsudveksling. Disse metadata bør være dynamiske så brugerne løbende kan kommentere og supplere erfaringerne, samt tilføje nye. På den måde vil det være muligt at samarbejde om at udnytte og udforske de pædagogiske muligheder, som ligger i store digitale ressourcer (Bang \& Dalsgaard, 2006).

Med henblik på at støtte samarbejdet om de digitaliserede biograf- og tvreklamer både i en forskningssammenhæng og i en læringssituation udviklede projektet Danske Reklamefilm i samarbejde med Zentrum für Graphische Datenverarbeitung (ZGDV) in Rostock, Tyskland et segmenterings- og annoteringsværktøj: VIRAT (VIdeo Research AssistanT). Med VIRAT er det muligt at separere digitale videoer i segmenter baseret på automatisk genkendelse af scener, eller segmenter der defineres af brugeren. Samtidig kan der skabes link mellem Microsoft Office dokumenter og segmenter i digitale videoer, og tekst kan overføres fra Microsoft Office dokumenter til VIRATs annotationsvindue. Endvidere er det muligt at regulere hastigheden hvormed videoer afspilles (mellem 0,25 og dobbelt normal hastighed) samt vise metadata fra Statsbibliotekets database. 
Ved at kombinere VIRAT og Statsbibliotekets søgefacilitet er det muligt for forskerne at identificere og downloade til egen computer de digitaliserede reklamer, som han eller hun ønsker at undersøge nærmere. Her kan de afspilles i forskellige hastigheder, segmenteres i scener samt annoteres med noter og kommentarer, der kan sendes til andre forskere i samarbejdsprojekter. Annotationerne kan også gemmes sammen med andre metadata med henblik på en løbende opbygning af viden om hver reklame. Især mulighederne for udvidet søgning, integrationen af kommentarer (tekst) i det audiovisuelle materiale og udvekslingen af noter og kommentarer med kollegaer ændrer forsknings- og læreprocessen i kollaborativ retning. 


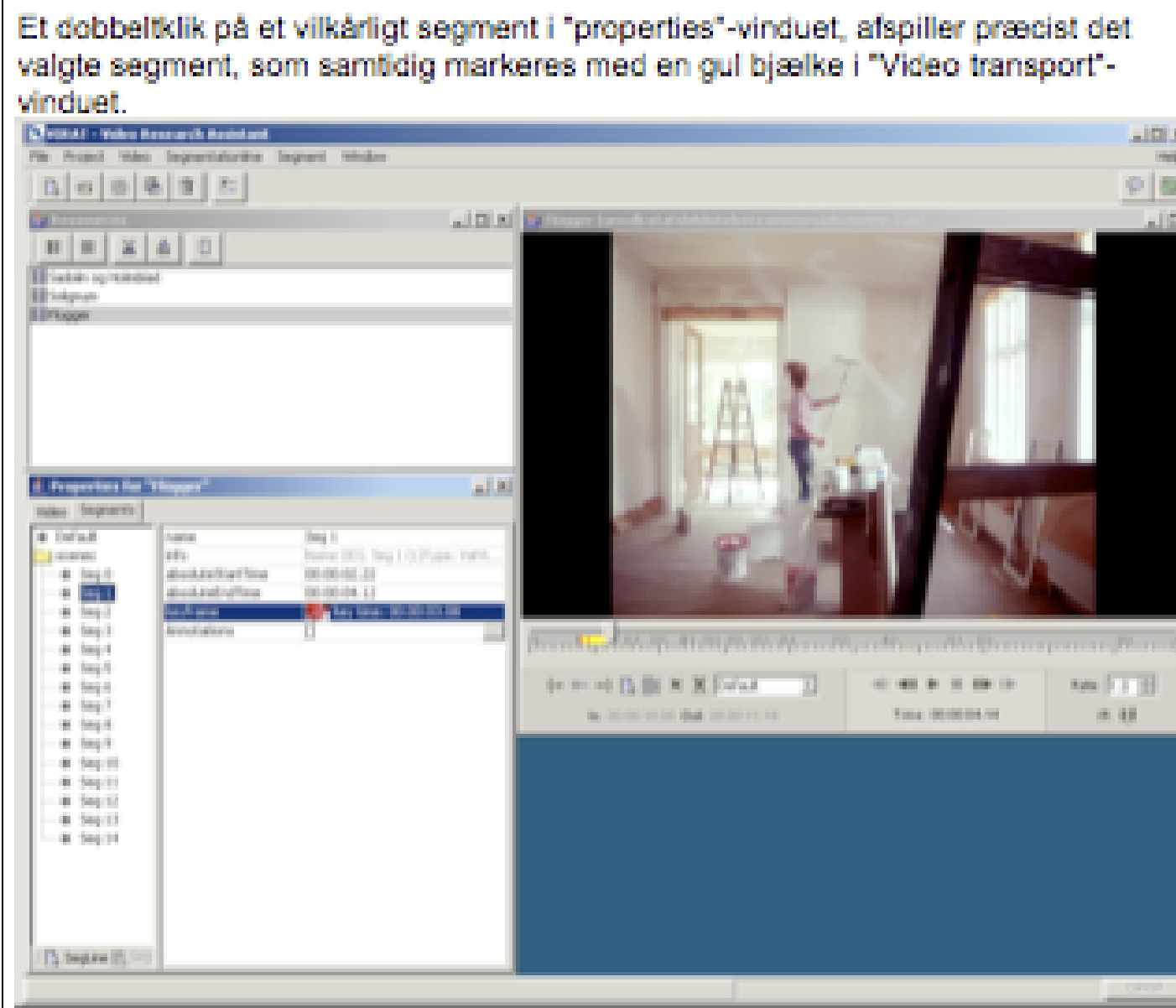

\section{Random segmentation}

Man kan ogsê valge at lade VRAT oprette helt tillekige segmentar.

Marker den film der enskes segmenteret i "resscurces" vinduet og valg hereftar "Segmentationline/Create a fancom segmentation" fra sverste menubjeike.

VIRAT abner herefter en dialogbox der fummer mulighed for dels at navngive den nye segmentlinie, dels at opstille fammer for det minimale og maksimale antal segmenter VRAT mă generere.

Figur 4. Video Research Assistant (VIRAT) - page 18

Erfaringerne med VIRAT-værktøjet peger på nogle af de muligheder for samarbejde mellem forskere og studerende, som også fremhæves i Hewlett Foundations visioner om en OPLI (Open Participatory Learning Infrastructure) (Atkins a.o., 2007) (se ovenfor) og i "OLCOS Roadmap 2012" (OLCOS, 2007):

"The current dominant paradigm of teacher- and subject-centred learning in formal education will have given way to a learner- 


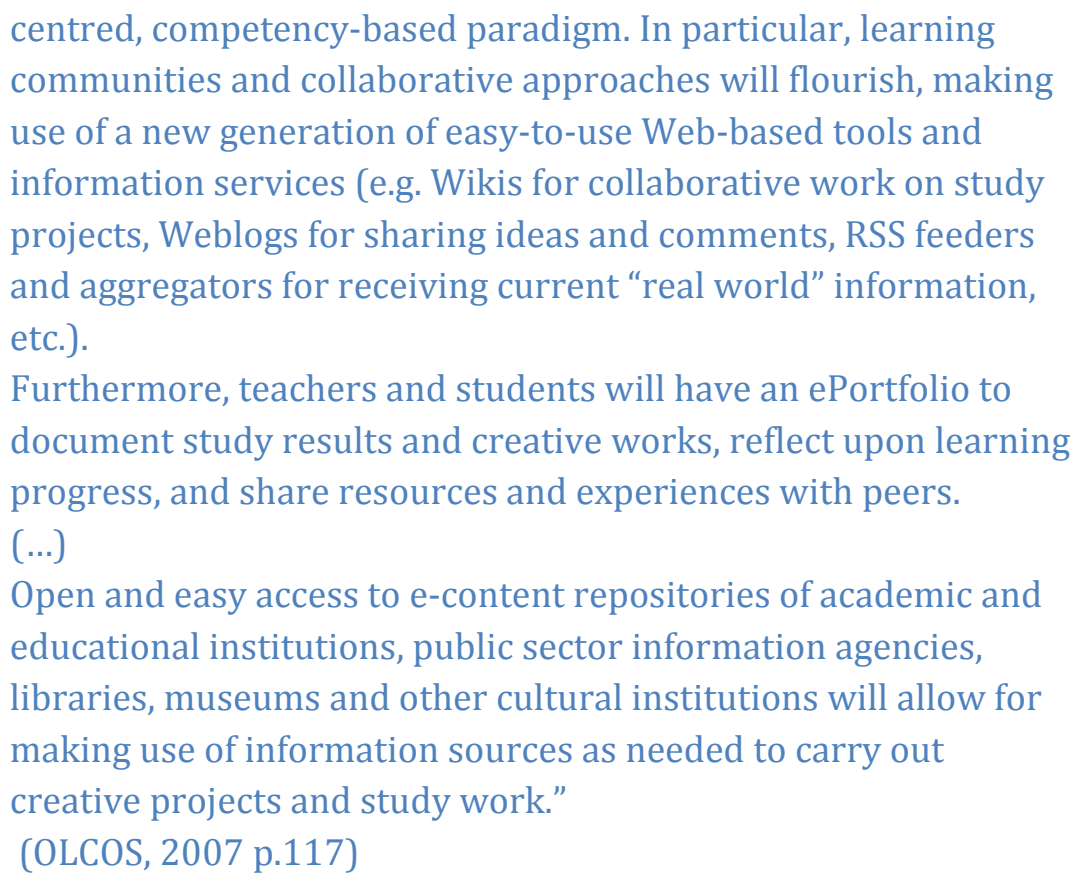

En integration mellem segmenterings- og annoteringsværktøjet VIRAT og Web 2.0-teknologierne vil yderligere styrke samarbejdsdimensionen i forskningsprojekter og i læringssammenhænge.

Jeg argumenterer ikke for udviklingen af en ny læringsplatform med alle dens risici for at stavnsbinde dens brugere, men for skabelsen af et åbent læringsmiljø, hvor de forskellige værktøjer er baseret på åbne standarder så de kan udveksle data gnidningsfrit med hinanden og bringes i anvendelse af brugeren - den lærende - efter behov. Det skal med andre ord være muligt at personalisere læringsmiljøet i forhold til den enkeltes situation.

På den måde vil det også være muligt at bygge bro over den eksisterende kløft mellem formel og uformel læring. Mellem den læring som finder sted i institutioner - skoler, universiteter, $\mathrm{mm}$., som er reguleret af undervisningsplaner og organiseret af lærere - og den læring som udspringer af besøg på museer, gallerier og biblioteker og i omgangen med massemedier uden at være reguleret af andet end den enkeltes interesse og nysgerrighed. Et netbaseret læringsmiljø som det skitserede, vil kunne understøtte og udbygge både bundne og spontane læreprocesser.

\section{Nye læringsscenarier med den digitaliserede kulturarv}

Erfaringerne fra Danske Reklamefilm peger kun på de pædagogiske muligheder som ligger i anvendelsen af en enkelt database som læringsressource. Det store gennembrud for anvendelsen af den digitaliserede kulturarv som læringsressource kommer den dag, hvor det er muligt at 
søge i alle databaser med digitale kulturarvsmaterialer på tværs af landegrænser - som målet er for Europeana.

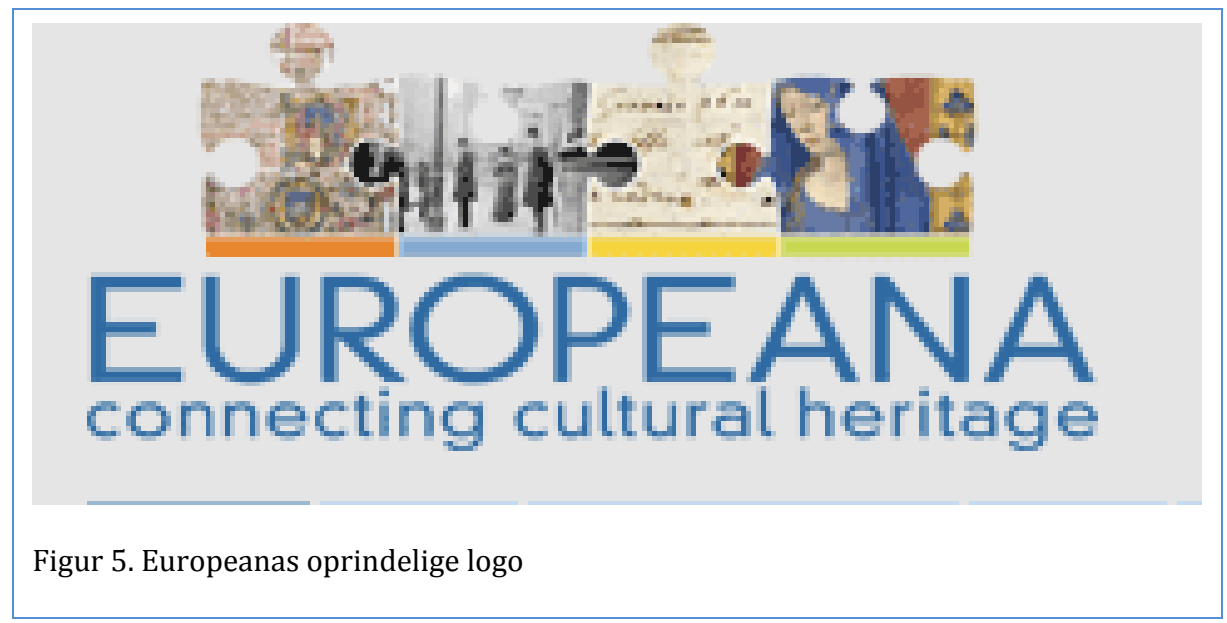

De fleste museer, gallerier og biblioteker er skabt og opbygget siden 1800tallets begyndelse parallelt med nationalstaterne og kan i stor udstrækning ses som et led i opbygningen af en national identitet. I et europæisk og globalt perspektiv er det imidlertid interessant at kunne følge kulturelle strømninger i samspillet mellem nationen og omverdenen i såvel historiske, idehistoriske, motiviske og tematiske som teknologiske rammer. Med tværgående adgang til kulturarven vil det f. eks. være muligt at studere hvordan "det orientalske" eller "det kinesiske" er blevet opfattet og indoptaget i den europæiske identitet med dens forskellige nationale variationer. 


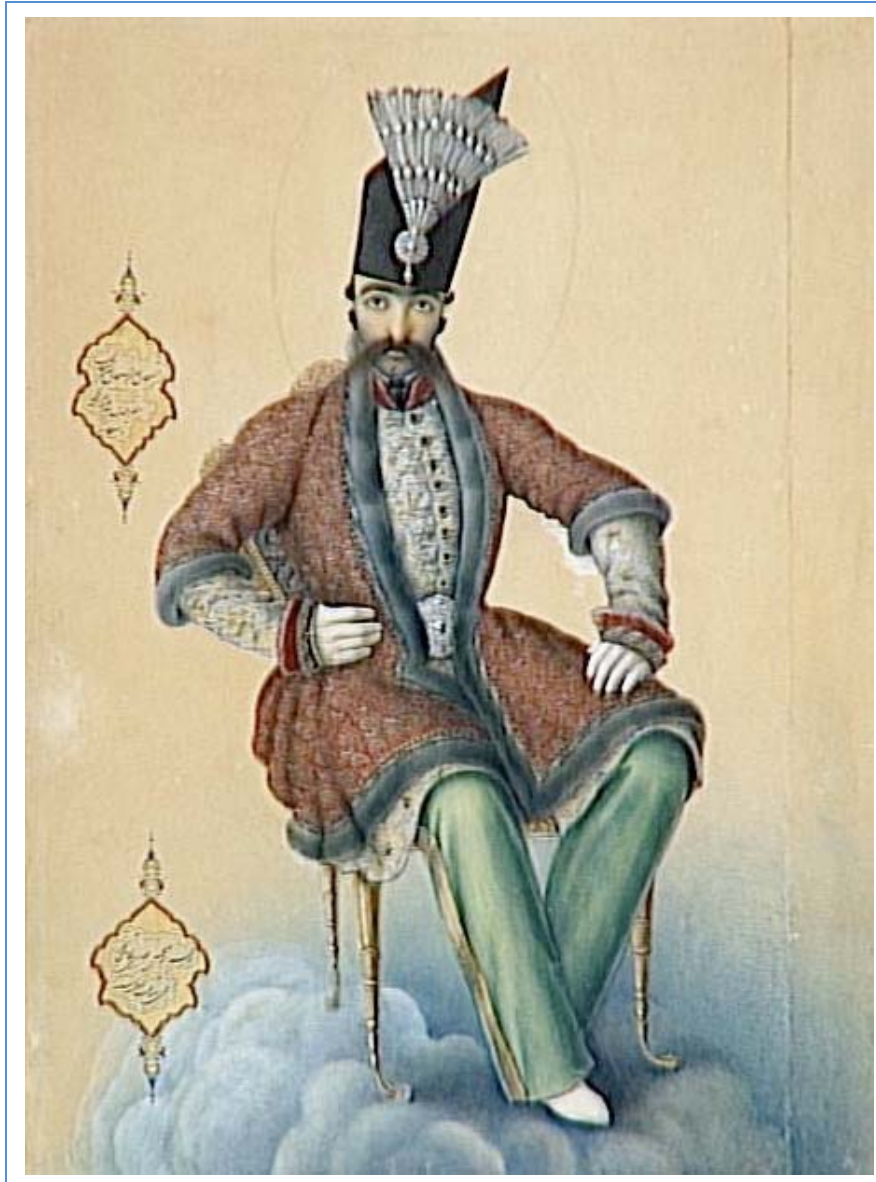

Figur 6. Miniature : Portrait de Nasir al-Din Shah, 1858, Paris, Musée du Louvre. http://www.europeana.eu/portal/fulldoc.html?uri=http://www.europeana.eu/resolve/record/0390 3/4F56AB402D4A172895E0BA19261F96BACCC45810\#

I undervisningssammenhænge vil det være oplagt på europæisk plan at etablere samarbejder mellem skoleklasser eller universitetskurser $\mathrm{i}$ forskellige lande, som med udgangspunkt i nationale digitale kulturarvsressourcer identificerer f. eks. opfattelsen af det orientalske over tid og sammenligner med den aktuelle opfattelse af det tyrkiske og/eller marokkanske. Analyserne kan fremlægges af alle deltagerne i en fælles wiki, der foruden selve analyserne med henvisninger til kulturarven også indeholder aktuelt brugerindsamlet materiale og brugergeneret indhold $\mathrm{i}$ form af f. eks. interviews med eller uden billeder. Brugerne - de studerende - inddrages derved ikke alene i analyseprocessen, men tillige i selve undersøgelsesprocessen gennem indsamling af dokumentation. Den efterfølgende diskussion af nationale forskelle i et europæisk perspektiv kan struktureres gennem anvendelsen af en weblog eller andre former for elektroniske diskussionsfora. Gennem udvekslingen af synspunkter vil det specifikt nationale blive tilført en europæisk dimension som bidrager til at forstå den nationale identitet som en del af en europæisk identitet. Til at 
understøtte projektet kan alle deltagerne bidrage til opbygning af en fælles link-ressource - social bookmarking og tagging - i f. eks. del.icio.us og/eller Flickr.

I uformelle læringssammenhænge ved f.eks. museumsbesøg er det også muligt at udbygge oplevelsen og tilføre vidensopbygningen nye dimensioner gennem inddragelsen af den digitale kulturarv og udnyttelse af Web 2.0-teknologier. Det vil således være oplagt at erstatte plancher og tekstskilte med elektroniske skærme med internetopkobling, hvor digitaliserede ressourcer fra andre museer og arkiver kan inddrages. Samtidig vil det være muligt at tilpasse oplysningsmaterialet til brugerne, så andre informationer fremvises, hvis den besøgende er i følge med sit 6årige barnebarn end hvis vedkommende kommer sammen med sin hustru. Dog skal det være muligt også selv at bladre i informationsmaterialet - evt. via download til sin mobiltelefon, så man ikke forstyrrer andre. Ligeledes bør det være en naturlig service fra museerne at den besøgende har adgang til alle udstillingsinformationerne over internettet i en periode efter besøget - måske 2 uger - så han eller hun kan vende tilbage til materialet for at genkalde oplevelsen og udbygget forståelsen. Dette kan eventuelt suppleres med besvarelse af faglige spørgsmål fra museets eksperter. Hvis dele af udstillingsmaterialet endvidere er tilgængeligt på museets web forud for besøget vil et sådant scenario betyde at den besøgende både kan forberede og efterbearbejde sit besøg.

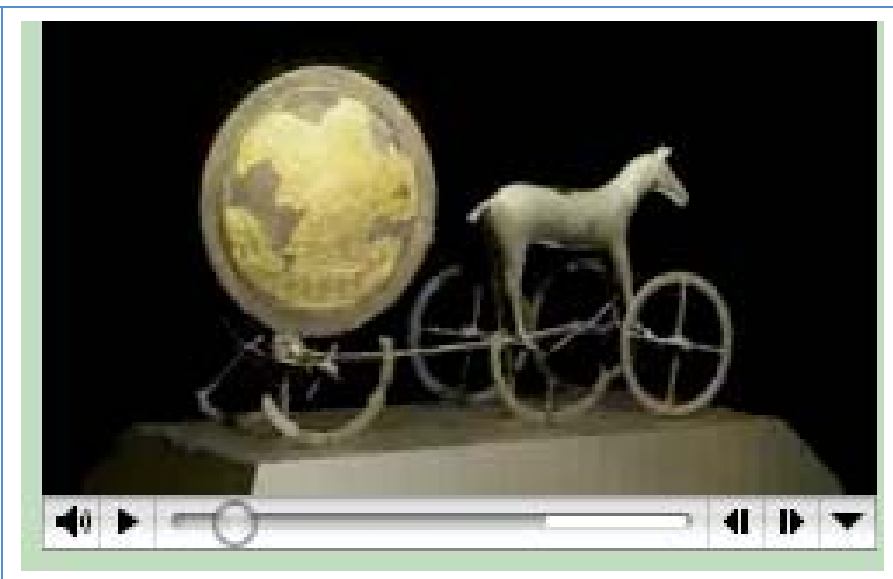

Figur 7. Nationalmuseets Web-tv om Solvognen, http://www.natmus.dk/sw58800.asp.

Der ligger også nogle nye potentialer for læring og videnstilegnelse generelt i de mobile teknologier som udvikles i disse år. Gennem integrationen af GPS og mobiltelefoni og suppleret med RSS-feeds bliver det muligt at få adgang både til informationer, man selv søger, og til informationer som er lagret med henblik på tilgang via abonnement. Man 
kan f. eks. gå gennem byen eller landskabet og få oplysninger om de bygninger og naturfænomener, man møder, såfremt oplysningerne er gjort tilgængelige. Det kan ske på initiativ af offentlige institutioner og organisationer eller som brugergeneret indhold på individuel basis i stil med Wikipedia.

I en ikke særlig fjern fremtid vil det f. eks. være muligt at abonnere på informationer om danske kalkmalerier, hvis det er ens interesse. Når man kører på landevejen vil man få en SMS om at der er nogle interessante kalkmalerier i den kirke, man passerer om få minutter. Inde i kirken vil man via sin mobil kunne sammenligne maleriers motiver med motiver i andre danske kirker via hjemmesiden www.kalkmalerier.dk. Endelig kan motiver også sammenlignes med andre middelalderlige motiver via søgning i europæiske databaser over digital kulturarv f. eks. Vatikanmuseet i Rom.

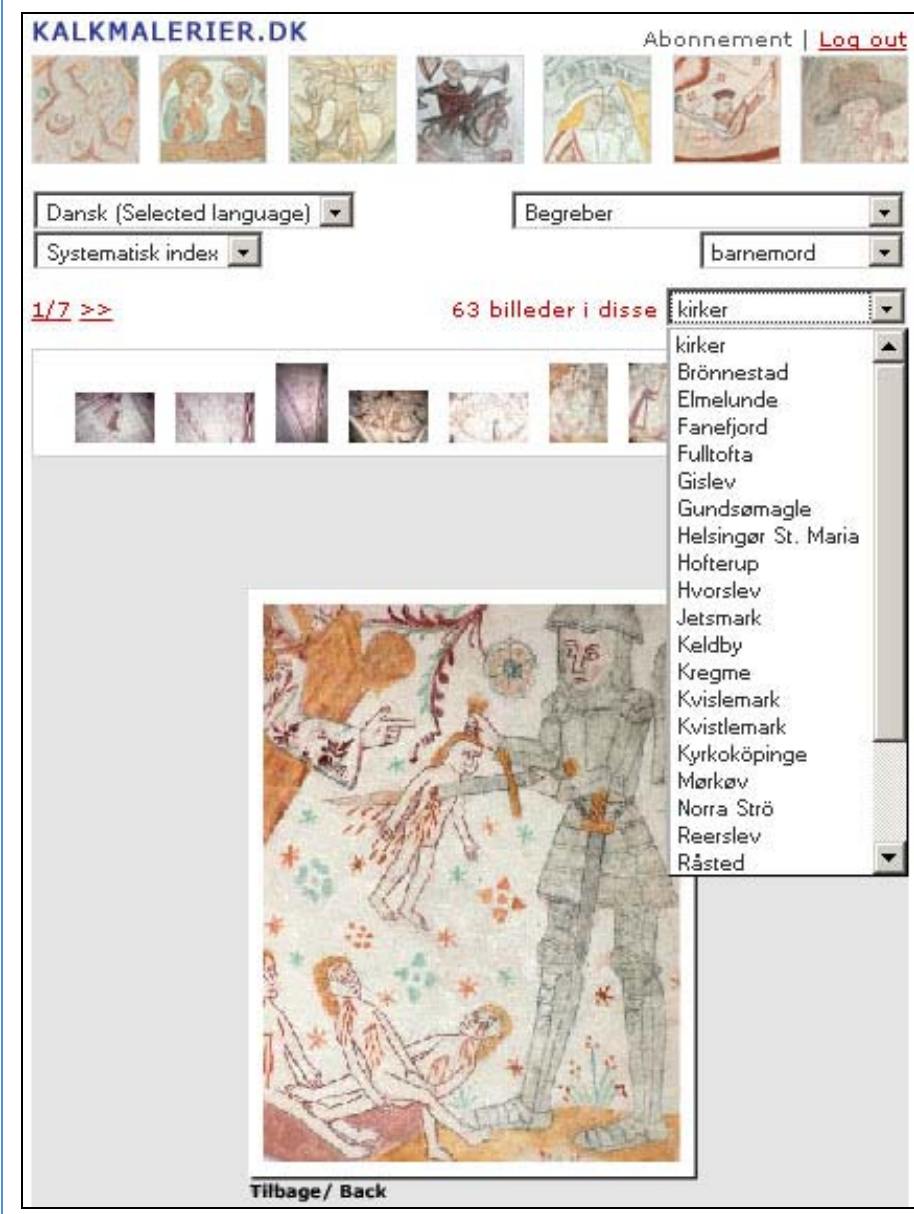

Figur 8. Hjemmeside med kategorisering af danske kalkmalerier (http://www.kalkmalerier.dk/). 
Det afgørende spørgsmål i et læringsperspektiv er om ikke denne adgang til informationer i form af digitale kulturarvsressourcer og brugergenereret netbaseret indhold, når vi ønsker det og hvor vi ønsker det, vil bidrage til et højere vidensniveau. Hvis det er tilfældet står vi på grænsen til en ny oplysningstid!

Men desværre kan det også være at denne mulighed kun vil blive udnyttet af de få, så Mathæus-effekten endnu engang kommer til at gøre sig gældende:

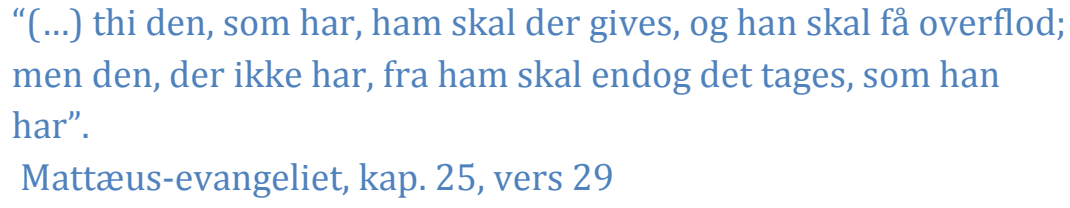
men den, der ikke har, fra ham skal endog det tages, som han har".

Mattæus-evangeliet, kap. 25, vers 29

\section{Litteratur}

Atkins, D., Brown, J. S. \& Hammond, A. L.: (2007): A Review of the Open Educational Resources (OER) Movement: Achievements, Challenges, and New Opportunities, http://www.oerderves.org/

Bang, J. \& Dalsgaard, C. (2006): Rethinking e-learning. Shifting the focus to learning activities, In: O Murchú, D. \& Sorensen, E. (eds.), Enhancing Learning Through Technology, Idea Group, Inc, p. 184-202

Bang, J, (2006): eLearning reconsidered. Have e-learning and virtual universities met the expectations? http://www.elearningeuropa.info/index.php?page=doc\&doc_id=7778\& doclng $=6$

Bang, J. (2007): "Short Narrative Advertising and Cultural Heritage, In p.o.v. - A Danish Journal of Film Studies p. 5-20

http://pov.imv.au.dk/Issue_23/section_1/artc1A.html

EU (2007): ICT Work Programme 2007-08, http://cordis.europa.eu/fp7/ict/

Europeana demo: http://dev.europeana.eu/home.php

Europeana, press release, Brussel, November 19, 2008

http://europa.eu/rapid/pressReleasesAction.do?reference=IP/08/1747\&f ormat $=\mathrm{HTML} \&$ aged $=0 \&$ language $=\mathrm{EN} \&$ guiLanguage $=\mathrm{en}$

Kolding Nielsen, Erland; Larsen, Svend; Madsen, Per Kristian; Noack, Johan Peter, Ohrt, Karsten \& Nissen, Dan: "Kulturarv ved skillevej - glemsel eller digitalisering", Politikens Kronik, 30.04.2009 
http://politiken.dk/debat/kroniker/article699392.ece

Kollias, A. (2007): Framework for e-Learning Content Evaluation. Position Paper

Koper, R. (2000). From change to renewal: Educational technology foundations of electronic environments.

http://dspace.ou.nl/handle/1820/38

Koper, R (2001): Modeling units of study from a pedagogical perspektive. The pedagogical meta-model behind EML, http://dspace.ou.nl/handle/1820/36

Lund, H. \& Rust, M. (2007): Video Research Assistant; Statsbiblioteket,

VIRAT-HjaelpDK.pdf

OECD (2001): E-learning:The Partnership Challenge. http://www.oecd.org/LongAbstract/0,2546,en_2649_33723_1898362_ 1_1_1_1,00.html

OECD (2005): E-learning in Tertiary Education. Where do we stand?

http://caliban.sourceoecd.org/vl=564418/cl=26/nw=1/rpsv/ 6670/v20 $05 \mathrm{n} 4 / \mathrm{s} 1 / \mathrm{p} 1 \mathrm{l}$

OECD (2007): Giving Knowledge for Free. The emergence of Open Educational Resources, http://www.oecdbookshop.org/oecd/display.asp?CID=\&LANG=EN\&SF $1=$ DI\&ST1=5L4S6TNG3F9X

OLCOS (2007): Open eLearning Content Observatory Services: Roadmap 2012, http://www.olcos.org/english/roadmap/download/

p.o.v. 23, A Danish Journal of Film Studies. Richard Raskin, ed. (2007): http://pov.imv.au.dk/Issue_23/POV_23cnt.html 